\title{
O PAPEL DA HISTÓRIA COMO FERRAMENTA DE EDUCAÇÃO AMBIENTAL NAS ESCOLAS DE EDUCAÇÃO INFANTIL
}

\author{
Juliana Andréia Christ Schizzi ${ }^{1}$, Clayton Hillig ${ }^{2}$ \\ ${ }^{1}$ Especialista em Educação Ambiental - Universidade Federal de Santa Maria - UFSM/RS \\ ${ }^{2}$ Doutor em Sociologia - Professor do Centro de Ciências Rurais, UFSM/RS.
}

julyschizzi@yahoo.com.br, hillig@smail.ufsm.br

RESUMO

O presente trabalho é o resultado da pesquisa que busca analisar as questões voltadas a Educação Ambiental, interpretação historiográfica, e a evolução desses processos. Verificando a percepção dos professores, funcionários, diretores, profissionais atuantes na educação infantil, analisando o que estão desenvolvendo e /ou colaborando para que de fato a Educação Ambiental seja efetivada nas Escolas. Qual é o papel da História quanto disciplina que visa o desenvolvimento humano e social, para a colaboração nesses projetos e se existe esta colaboração. Pretende-se abordar o papel da história como ferramenta para a formação de cidadãos, e analisar a coligação da História ambiental com a realidade atual e suas transformações no decorrer dos anos, bem como verificar como a educação ambiental é trabalhada na base de nossa sociedade/ as crianças, através de seus articuladores - os professores; analisar a percepção ambiental das crianças após realização de trabalhos práticos de educação ambiental na EMEI Paraíso da Criança, no Município de Horizontina / RS, com crianças de 4 / 5 anos; sensibilizando a criança com trabalhos concretos.

Palavras-chave: história, educação ambiental, educação infantil, ferramenta.

\section{ABSTRACT}

This work is the result of research that aims at analyzing matters dealing with Environment Education, historiographic interpretation and the evolution of these processes. Checking the perception of teachers, workers, directors, active professionals in child education, analyzing what they are doing and or cooperating that in fact Environment Education become effective in schools. The role of History as a subject that seeks human and social development, to cooperate with these projects and if this cooperation exists. The role of History is seen as a tool for the formation of citizenship and to analyze the connection of Environment History with current reality and its transformation along the years, as well as checking how Environment Education is done at the base of our society / the children, by the people that handle it - the teachers; to analyze the environment perception of children after performing practical environment education activities at EMEI Paraíso da Criança, in the city of Horizontina - RS, with 4 / 5 year old children; motivating children with practical activities. Realized with the completion of that environment education neds 
to be further elaboborated with the children clearly and objective, tutting theory into practice through projects where children are the performers.

Key words: history, environment education, child education, tool.

\section{INTRODUÇÃO}

O presente trabalho vem expressar o resultado da pesquisa realizada, cumprindo as exigências necessárias ao término do Curso de Pós-Graduação em Educação Ambiental, sendo que o tema da pesquisa aborda "O papel da História como Ferramenta de Educação Ambiental nas Escolas de Educação Infantil". Busca analisar as questões voltadas a Educação Ambiental, relacionadas à interpretação historiográfica, e a evolução desses processos; verificando a percepção dos professores, funcionários, diretores, atuantes na Educação Infantil em seus diversos campos de saber, analisando o que estão desenvolvendo e /ou colaborando para que de fato a Educação Ambiental seja efetivada nas Escolas, refletindo qual é o papel da História quanto disciplina e área de saber para a colaboração nesses projetos, se existe esta colaboração e o que se pode melhorar relacionando a Educação Infantil como base do crescimento intelectual da criança, e usando da educação ambiental como forma de concepção de mundo e amadurecimento de ações voltadas a um meio ambiente melhor e mais próximo da realidade que o corpo discente convive diariamente; bem como analisar a percepção ambiental das crianças após a realização de trabalhos práticos de educação ambiental na EMEI Paraíso da Criança, localizada no Município de Horizontina /RS, com a turma do Jardim I (crianças de 4-5 anos).

Questões voltadas à preocupação ambiental ascenderam-se há três décadas, sendo que estão se acentuando na atualidade os problemas causados pela falta da conscientização do ser humano; o homem quando aprende a dominar o meio ambiente, aprende a usufruir de suas riquezas naturais; sendo que estas com o tempo foram se esgotando e hoje muitas delas extinguiram-se. A pesquisa não se limita apenas à análise, mas também contribui através de reflexões históricas e percepções fundamentadas com práticas pedagógicas na Educação Infantil voltada a Educação Ambiental para o desenvolvimento intelectual e humano desses sujeitos crianças da Educação Infantil.

Portanto para a execução da primeira parte dessa pesquisa foram levantados dados bibliográficos, referentes ao tema, através de uma pesquisa documental, utilizando-se o método qualitativo para uma melhor compreensão do tema; num segundo momento foram realizadas práticas pedagógicas com as crianças da Educação Infantil para sondagem de seus conhecimentos e percepções ambientais fundamentadas no convívio familiar; num terceiro momento foram obtidos por meio de entrevistas realizadas junto ao corpo docente e funcional da Escola Municipal de Educação Infantil Paraíso da Criança - Horizontina /RS à percepção dos educadores como norteadores para a concretização da Educação Ambiental na Escola. 


\section{REVISÃO BIBLIOGRÁFICA}

\section{Transformação ambiental: um pouco de história}

A historicidade revela como é interessante desvendar, analisar, interpretar e estudar experiências passadas, através da história deixada pelo sujeito que a viveu. Tentar compreender crenças e mitos; analisar o modelo de sociedade que existia no passado e o quanto ela evoluiu, requer muita análise e interpretação historiográfica.

Portanto, interpretando a História teórica do surgimento da origem da vida humana na terra, por exemplo, dá para perceber o quanto ela se transformou e evoluiu, e ainda está em processo de evolução.

Teorias que formam a concepção do homem como ser atuante na evolução científica, social, moral, global, cibernética do Planeta do qual fazemos parte integrada e integrante, podemos verificar o quanto somos responsáveis pela situação atual e o que podemos fazer para amenizar os impactos pelos homens gerados.

\section{Concepção de sociedade de risco e problemas ambientais}

O impacto do ser humano sobre o meio ambiente atinge uma escala global; a sociedade sofre as consequências. As Cidades, Nações, Estados, independentemente de cor, partido político, credo, cultura e conta bancária sofrem diariamente esses impactos causados pela degradação e falta de conscientização ecológica do homem em relação ao meio ambiente no qual está inserido.

O impacto do desenvolvimento tecnológico e moderno desenfreado gerou e agravou o desenvolvimento da pobreza, das más condições de vida e principalmente o de suprir as necessidades básicas do ser humano para que este possa viver com dignidade; o homem passa a valorizar mais os bens materiais e não mede esforços para conquistá-los, acarretando assim para o meio ambiente, destruição, degradação e inúmeros problemas gerados por esse desenvolvimento sem planejamento; como a contaminação da água, do solo, do ar, à violência e tráfico de animais silvestres, derrubada ilegal de madeiras, entre outros; danos causados que podem se tornar irreversíveis à natureza.

Segundo James Lovelock (2007) que escreveu uma importante reportagem sobre o Aquecimento Global, problema global, que nos afeta simultaneamente, enfatiza que "a terra está entrando em um estado febril, que pode durar mais de cem anos" (2007, p.37), o Aquecimento Global é uma realidade palpável, que está nos afetando de inúmeras maneiras, cujas muitas vezes não sabemos como proceder para tentar amenizar seus efeitos. James relata ainda, que somos responsáveis por esta nova onda febril e que sofremos duramente as suas consequências.

Muitas pessoas acreditam que o problema será dos outros; por simples falta de informação e/ou ignorância, preferem deixar a situação como está, pensando individualmente e preconceituosamente, que com eles nada irá acontecer.

Segundo textos propostos por Soares (2000), este colabora dizendo a respeito de um novo modelo / tipo de sociedade, 
"a sociedade de risco (U.BECK); uma sociedade que não está segura, pois desconhece as reais consequências destes males globais e na qual vivemos em um estado de permanente de incerteza, pois o passado é cotidianamente apagado e o futuro totalmente indefinido. Esta incerteza chama atenção para o fato de que, o controle da ciência e da tecnologia deve ser tão importante para as questões ecológicas, como o controle do meio ambiente [...]. O desenvolvimento insustentável e sua cultura técnica / performática e do desperdício deve ser substituído por um desenvolvimento sustentável de enfoque comunitário, que priorize o princípio da equidade social por sobre a eficiência alocativa, rompendo-se com a visão tecnocrática que subordina a participação da sociedade civil aos mecanismos do mercado" (SOARES, 2000).

As cidades enfrentam problemas ambientais de enfoque global, pois segundo Nefussi e Lico (2000) as enchentes que ocorrem nos grandes centros, por exemplo, decorrentes da impermeabilização do solo; da erosão do solo e acúmulo de lixo em lugares inadequados é consequência da falta de conscientização ecológica. Também enfatiza que os problemas de saneamento são precários e se agravam pelo crescimento significativo da população, sobretudo nas periferias das grandes cidades.

\section{Sociedade de risco: a realidade social}

A Revolução Industrial contribuiu para que o sistema capitalista fosse instaurado e a globalização reinasse; países desenvolvidos buscaram através deste sistema dominação e aquisição de riquezas; o lucro era visto como moeda de barganha, e quem mais possuía esta moeda, mais poderia barganhar, os pequenos comerciantes eram engolidos pelos predadores, estes hoje chamamos de multinacionais; estas visam somente o lucro e geração de excedente; o ser humano, é considerado máquina braçal; o homem passa a ser meramente uma mercadoria e quem não está se adaptando a estas mudanças passa a deixar de ser considerado "gente"; o ser humano vem em último lugar, passa a ocupar o lugar de operador de máquinas e àqueles que não conseguem uma oportunidade de trabalho acaba por ser marginalizado por este novo sistema.

Montenegro e Duarte (2008) afirmaram que o processo industrial foi gradual, e que teve um reflexo real o aumento de renda, poder de compra, bem estar de todos os integrantes da sociedade.

Em contrapartida, a caracterização de uma sociedade pós-industrial foi extremamente rápida, o que inegavelmente acabou por contestar diretamente os modos de se pensar, os esquemas mentais, as tradições até então adotadas, a cultura ideal e social de milhares de pessoas, questionamentos inerentes a todas estas mudanças. Assim, na sociedade oriunda deste processo, temos muitos questionamentos que ainda estão presentes, fruto de uma intrincada teia de conceitos que devem ser revisadas. (MONTENEGRO e DUARTE, 2008, 596) 


\section{METODOLOGIA}

\section{Tipo de Pesquisa}

Para a realização desta pesquisa foi feita uma coleta de dados documentais e bibliográficos, bem como entrevistas objetivas e subjetivas com o grupo funcional da Escola Municipal de Educação Infantil Paraíso da Criança, localizada no Município de Horizontina / RS partindo da interação cotidiana na mesma com observações e apontamentos diários de pesquisa bibliográfica para investigação histórica, sociológica e pedagógica, bem como fotografias para ilustrar a realidade da Escola, e trabalhos práticos com as crianças do Jardim I, investigando a realidade escolar. Escolheu-se a análise documental como forma de abordagem da pesquisa qualitativa por apresentar algumas vantagens, como constituir-se como fonte real.

Como procedimento metodológico desta pesquisa adotou-se o método qualitativo e as técnicas de pesquisa de analise documental. As pesquisas qualitativas caracterizam-se pela utilização de metodologias múltiplas, sendo as mais utilizadas a observação (participante ou não), a entrevista em profundidade e a análise de documentos (KIST 2009 apud DENKER, 1998,103). Segundo Kist apud Tozoni-Reis (2005 p.270) “[...]precisamos imprimir à exploração da realidade educacional um caráter qualitativo, isto é, qualquer que sejam os dados revelados no processo de investigação dessa realidade, as análises exigem interpretações qualitativas." (KIST, 2009,53).

Estruturou-se o trabalho em capítulos, sendo que estes buscam enfocar uma breve análise historiográfica do que é educação ambiental na atualidade, suas contribuições históricas e as mudanças percebidas no decorrer dos anos; o segundo capitulo busca analisar uma das consequências do não comprometimento da sociedade com o meio ambiente gerando assim a sociedade de risco, segundo SOARES, (2000). apud U.BECK

Num primeiro momento foram realizadas entrevistas subjetivas e conversas informais com professores e funcionários para uma socialização de ideias e pensamentos; após interação e convívio com professores e funcionários foi feita uma entrevista de dados, objetivamente para fazer comparativos, tabelas e gráficos; o próximo passo foi interagir diretamente com as crianças desenvolvendo laços de afetividade, amizade, sensibilizando-as de que são sujeitos participativos e atuantes na realidade ambiental que Ihes cercam; objetivou-se contextualizar a educação ambiental com práticas e concepções.

\section{Etapas da pesquisa}

A execução do trabalho seguiu em etapas:

$1^{\circ}$ Etapa - Seleção de materiais bibliográficos para análise e reflexão, para a construção do Referencial Teórico.

$2^{\circ}$ Etapa - Contato com a EMEI Paraíso da Criança para maior interação e sondagem tanto no meio funcional quanto no meio pedagógico e realização de coleta de dados.

$3^{\circ}$ Etapa - Entrevista com professores e funcionários da Escola. 
$4^{\circ}$ Etapa - Interação com as crianças do Jardim I, buscando verificar seus conhecimentos sobre a educação ambiental, sensibilizando-os para a realidade em que vivem de forma prática e concreta.

5a etapa - Discussão dos resultados e elaboração final da monografia.

\section{Coleta das Informações}

Foi necessário realizar pesquisa para levantamento de dados, entrevistas, como forma de obter informações sobre os pontos de vista e reflexões dos funcionários da Escola, buscando interpretar e refletir como a educação ambiental é trabalhada com a educação infantil, verificando relações com a história e se existe efetiva participação neste processo.

O procedimento utilizado para a realização da coleta de dados foi através de entrevistas objetivas e subjetivas, observações diárias, com apontamentos e fotografias para ilustrar a realidade vivenciada, pesquisa qualitativa; interação com as crianças, através de um projeto proposto por minha prática na educação infantil, onde as crianças interagiram com o meio ambiente, plantando um canteiro de flores, observando suas percepções do antes e do depois desta prática, com ilustrações e gravuras expressadas por suas idéias.

\section{Participantes do estudo}

Seguindo o projeto inicialmente proposto escolheu-se 15 colaboradores: professores e funcionários da EMEI Paraíso da Criança, para analisar e refletir suas contribuições e reflexões sobre o tema abordado.

Após entrevista foi elaborado um projeto para interação com as crianças de faixa etária de 4 a 5 anos, para sondagem de sua percepção do antes e do depois da prática pedagógica realizada.

\section{Análise dos Dados}

Pensar em Educação Ambiental é pensar na responsabilidade social que cada cidadão desempenha na sociedade; refletir que o meio ambiente não é somente a Amazônia, e que "separar o lixo" não é a salvação de todo o problema ambiental globalizado, mas é um começo; gerando assim inúmeras indagações.

Alternativas de prevenção seriam mais aconselháveis na questão de "cuidar" do meio ambiente; sensibilizar as pessoas no seu comprometimento de ajudar a não degradar é uma forma prática de tentativas de mudanças culturais, e rupturas de paradigmas pré-estabelecidos e/ou formados e passados de gerações. Apontar defeitos sem embasamento para tais é soltar palavras ao vento, e estas se perdem no caminho.

Refletindo e interpretando as entrevistas realizadas com educadores e profissionais da área, citadas anteriormente; fazem-nos pensar o que podemos fazer para superar nossos próprios conceitos, e o que podemos fazer em relação a sensibilizar as crianças, neste caso, da creche onde foi realizada esta pesquisa; mas também refletindo utopicamente para as futuras gerações; Barcellos (2009) exemplifica, citando, 
Atuando enquanto alternativa de ação educativa nesse campo, a educação ambiental pode abrir novas possibilidades de interagir junto ao cotidiano social, bem como junto às pessoas e à sociedade. Diante disso, a educação ambiental pode oferecer oportunidades de ações que estimulem as pessoas a interagirem e a atuarem enquanto sujeitos de transformação no ambiente no qual vivem, demonstrando, assim, de que maneira a participação no ambiente comunitário pode estimular a cidadania e abrir novos canais de participação na sociedade. (BARCELLOS, 2009, 13).

Percebe-se ao compreender as idéias propostas pelo autor que a temática ambiental vem assumindo papel de destaque, despertando o interesse das comunidades, devido o enfoque da mídia; e percepção de que algo precisa ser feito.

Verifica-se com as análises das entrevistas que os educadores desempenham um enorme papel como articuladores, mas que muitas vezes é necessário uma reflexão cognitiva para descobrir que caminho é necessário seguir; muitos dos entrevistados relataram suas experiências de vida acadêmica e de convívio escolar; orientam através de suas percepções o que se deve fazer, e o que na maioria das vezes fazem em sua área de convívio profissional.

Apreciando os gráficos a seguir, percebe-se o quanto a educação ambiental precisa ser trabalhada na educação infantil de forma clara e objetiva; mas analisa-se que a educação tradicional vem sendo modificada aos poucos e que se busca interagir de forma libertadora, mesmo que seja teoricamente.

\section{RESULTADOS E DISCUSSÃO}

\section{Características do Corpo Funcional}

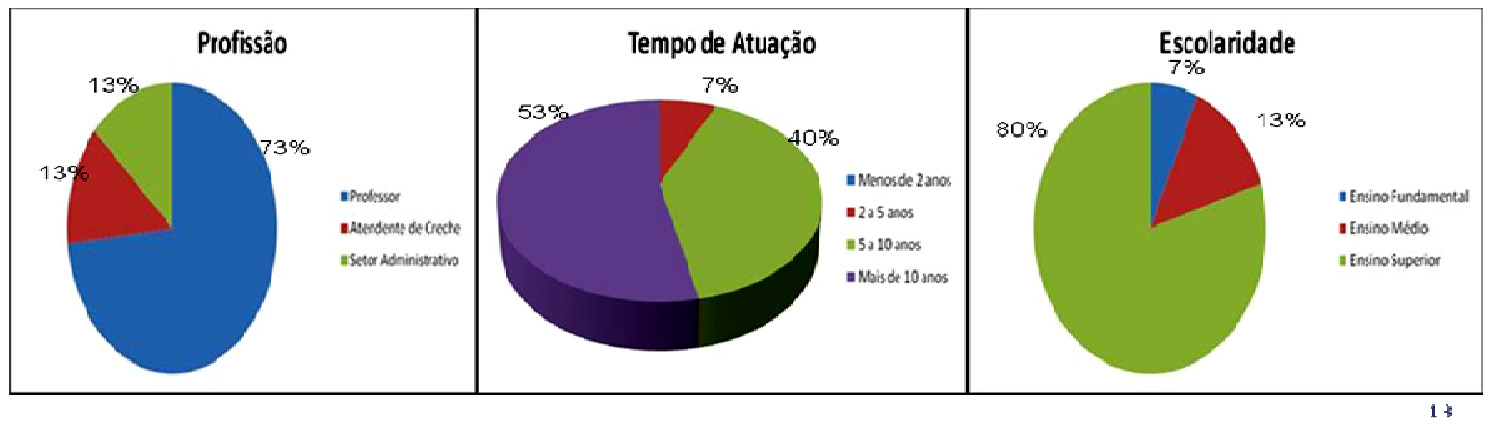

Gráfico 1, 2 e 3 - Referente a Profissão, Tempo de Atuação e Escolaridade dos Entrevistados.

Em relação a profissão, $73 \%$ são professores, 13\% trabalham no setor administrativo e 13\% são atendente de creche; já em relação ao tempo de atuação, 53\% trabalham na área a mais de 10 anos, $7 \%$ de 2 a 5 anos e $40 \%$ de 5 a 10 anos; quanto a escolaridade $80 \%$ dos entrevistados possuem Ensino Superior, 7\% Ensino Fundamental e 13\% Ensino Médio. 


\section{Percepções do Corpo Funcional em relação à Educação Ambiental}

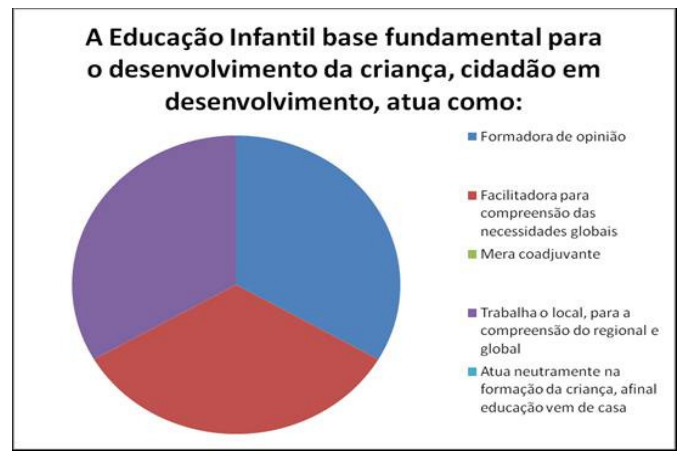

Gráfico 4 - Papel da Educação Infantil no desenvolvimento da criança

Interpretando os dados do gráfico anterior; $33 \%$ dos entrevistados acreditam que a Educação Infantil é formadora de opinião e 33\% analisa que a Educação Infantil é facilitadora para a compreensão das necessidades globais do educando, nenhum entrevistado apontou a educação ambiental como mera coadjuvante; $33 \%$ interpreta que a educação ambiental trabalha o local, para compreensão do regional e global.

Referente ao questionamento: Você acredita que a História exerce papel importante na Educação Infantil, como ferramenta de Educação Ambiental?

Todos os entrevistados afirmam que a História exerce papel importante na Educação Infantil como ferramenta de Educação Ambiental, cometam que é importante aprender a cuidar do meio ambiente desde pequeno, para que quando adultos possam ser conscientes de seu papel ambiental; citam que a criança aprende melhor e mais fácil que um adulto, aprendendo através da ludicidade; citam também que atualmente as catástrofes ambientais são muito mais freqüentes que em décadas anteriores. Justificando o papel da história como ferramenta de educação ambiental; os entrevistados apontam que a compreensão dos fatos históricos ajudam a fazer com que as crianças assimilem o que está acontecendo na atualidade, ou seja, no meio em que estão inseridas, de forma simples e não complexa.

\section{Atitudes Cotidianas em relação à prática de Educação Ambiental}

Com a intenção de analisar as atitudes diárias dos entrevistados como forma de contribuição prática de suas atitudes em relação ao meio ambiente para que possamos aprender, foi feita a seguinte pergunta:

- Quais são as suas atitudes diárias, casa - trabalho, em relação à preservação do meio ambiente? Você se considera um ambientalista?

Em relação a se considerar ou não um ambientalista, quatro pessoas responderam afirmativamente, sete pessoas ficaram em dúvida e/ou não se consideram plenamente e quatro 


\section{Monografias Ambientais \\ (Revista Eletrônica do CEspEdAmb-CCR/UFSM)}

REMOA

pessoas não se consideram ambientalistas.

As atitudes diárias conforme os entendimentos de atitudes ambientais mais citadas são a separação do lixo, a economia da água, economia de energia elétrica, plantio de árvores, utilização da sacola ecológica (produto elaborado em tecido, lavável, resistente e retornável) no supermercado como forma de evitar o uso de sacolas plásticas.

Alguns citam que busca educar seus filhos a preservar/economizar o máximo de água e energia elétrica, como por exemplo, fechar a torneira enquanto escovam os dentes. Também foi apontado que não há política municipal de separação do lixo, sendo que a entrevistada costuma separar o lixo orgânico do reciclável, mas que no recolhimento o caminhão do lixo não separa o tipo de material e mistura tudo.

As contribuições dos entrevistados apontam que estes em sua maioria praticam a educação ambiental da forma que julgam corretas, buscam trazer essas práticas para o seu cotidiano escolar.

Interações com as crianças do Jardim I, buscando verificar seus conhecimentos sobre a educação ambiental, sensibilizando-os para a realidade em que vivem de forma prática $e$ concreta.

Investiga-se num primeiro momento, qual a bagagem de conhecimento que as crianças da turma Jardim I, possuem sobre Educação Ambiental e /ou Meio Ambiente, o que é meio ambiente na visão de crianças de faixa etária entre 4 e 5 anos de idade. Busca-se refletir o quanto o professor tem o dever de desempenhar o papel de articulador e que muitas vezes comete falhas significativas pensando que estava agindo corretamente.

Segundo as gravuras a seguir, percebe-se na interpretação das crianças o que a mídia mostra na televisão sobre Meio Ambiente e/ou o que é comentado em suas residências, debatida por seus familiares e assimiladas pelas crianças.

Questiona-se o que entendem por Meio Ambiente:

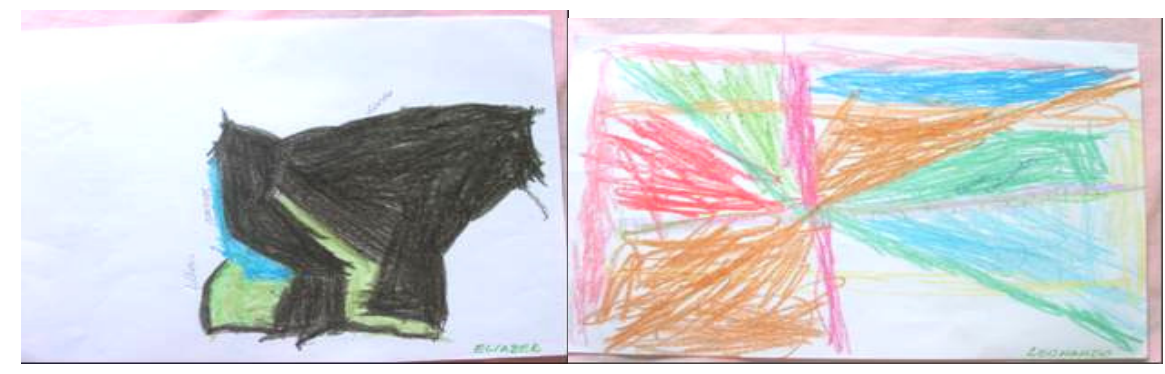

Figura 1 e 2 - Meio Ambiente (casa, canos e folhas) e Meio Ambiente (canos de esgoto)

Essas duas crianças interpretaram o meio ambiente, como o que a televisão mostra, foi indagado o porquê destes desenhos e um aluno respondeu que ele viu na Televisão canos de esgotos jogando sujeira nos Rios.

Reflete - se em primeiro lugar, qual a bagagem cultural das mesmas, e qual o papel da Escola em relação a esta problemática; aos professores, enfoca que atitudes tomar e como fazer para mostrar para a criança que o meio ambiente não se resume em o que os noticiários mostram 
na televisão.

Segundo o Ministério da Educação e Desporto (1998) remetido pelo Ministério da Educação, analisa-se que a criança sofre muita influência dos meios de comunicação, conforme desenho acima, cujo ilustra seus pensamentos sobre o Meio Ambiente em que estão inseridos.

Piaget (2001) afirma que " o desenho é uma forma de função semiótica que se inscreve a meio caminho entre o jogo simbólico, cujo mesmo prazer funcional e cuja mesma autotelia apresenta , a imagem mental , com a qual partilha e o esforço da imitação do real." (PIAGET,2001,p.57).

Refletindo e analisando as gravuras,bem como repensando as entrevistas com os professores da escola; percebeu-se que é necessário um trabalho mais concreto de educação ambiental com as crianças da educação infantil; não importando a idade, faixa etária, mas sim analisando quais são suas perspectivas em relação ao meio em que estao inseridas; por esta preocupação, optou-se pela elaboração de um projeto simples e de fácil acesso para as crianças, entitulado: "Adote um Jardim", inicilamente buscou-se integrar toda a Escola, mas percebemos que alguns professores tinham outras prioridades, o trabalho foi executado pela turma Jardim e auxílio constante da professora titular da turma.

O trabalho proposto foi executado com o Jardim I, uma turma de 33 alunos, crianças com 4 e 5 anos de idade; foi um grande desafio trabalhar com elas, pois todas queriam ajudar ao mesmo tempo; por intervenção da professora Regente, as crianças que executassem as tarefas propostas durante a semana, obedecessem as regras e cumprissem suas responsabilidades, poderiam participar do projeto.

Muitas foram as dificuldade enfrentadas, uma foi que devido a política de prevenção da dengue os pneus foram recolhidos e mandados para fora do Município, não conseguindo encontrar pneus disponíveis e sem custo; após muito diálogo e longa procura um agricultor fez a doação de dois pneus para o jardim; então estes foram lavados e pintados pelas crianças, como mostra a figura abaixo:

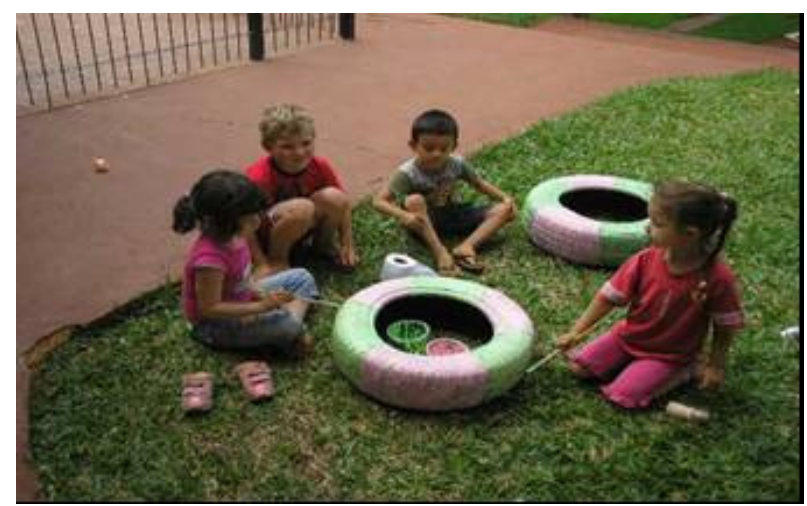

Figura 3 - Etapa de pintura dos Pneus

Após a lavagem, pintura e secagem dos pneus, a equipe diretiva da Escola buscou com o poder municipal aquisição de materiais para o plantio do Jardim; mudas de flores, terra especial, adubos, etc. 


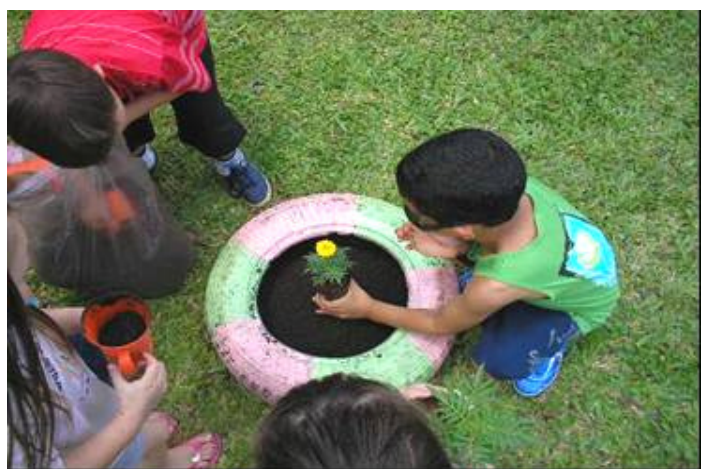

Figura 4 - Crianças executando o projeto

As crianças se divertiram com a interação, a professora Regente e equipe diretiva interferiram quando acharam necessário; escolhendo o local para o plantio.

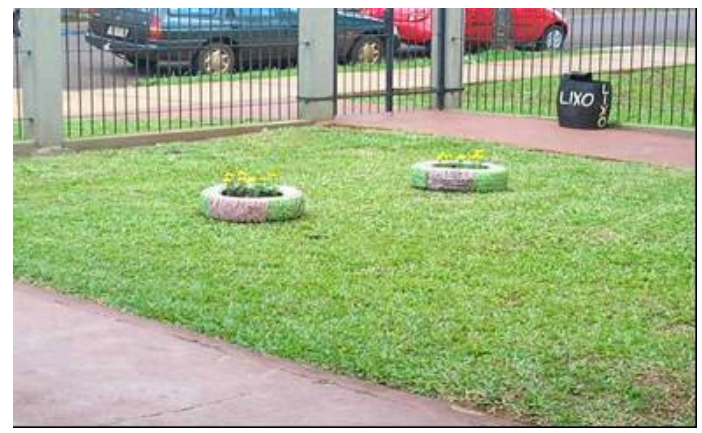

Figura 5 - Resultado Final

Analisar essas pequenas ações e perguntar: o que mudou com isso? Qual era o objetivo dessa atividade? Responde-se que através desta simples atividade as crianças puderam modificar suas opiniões sobre o que é Educação Ambiental, interagindo e praticando ações. Mostrando que trabalhos simples podem ser realizados de forma prática e concreta.

Uma semana depois do plantio do Jardim, este não era mais novidade para as crianças e o que fazer a este respeito? Muitos ajudantes do dia não regavam as flores, alguns esqueciam qual era seu dia, então fomos passear no bosque próximo a EMEI, para que as crianças refletissem sobre suas atitudes. Trabalhou-se no passeio a História, como era antes de os homens chegarem aqui, que o bosque não teve interferência humana, que as árvores, flores nasceram por conta e/ou por alguns fatores da natureza, como vento, passarinhos.

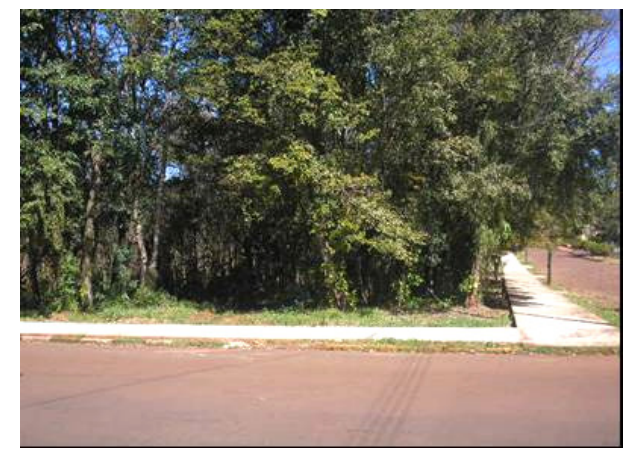

Figura 6 - Bosque próximo a EMEI 


\section{Monografias Ambientais \\ (Revista Eletrônica do CEspEdAmb-CCR/UFSM)}

REMOA

Neste passeio as crianças observaram como as plantas estavam bonitas, as flores coloridas e não murchinhas como as do Jardim deles; buscou-se mostrar para as crianças que é necessário comprometimento com o Meio Ambiente, pois vivemos uns dependendo dos outros para vivermos bem; enxergaram a diferença de plantas que nasceram sem a interferencia humana e daquelas que eles plantaram, ambas precisam de cuidados diferenciados e que as pessoas como seres humanos racionais devem repensar suas atitudes diárias e seu comprometimento.

Ao chegar na Escola pediu-se para que eles desenhassem como o meio ambiente deveria ser, e que diferenças perceberam, através de mudanças de atitudes, utilizando de diversas técnicas como desenhar com Giz molhado e desenhar com Giz de cera, dividiu-se a turma em dois grupos

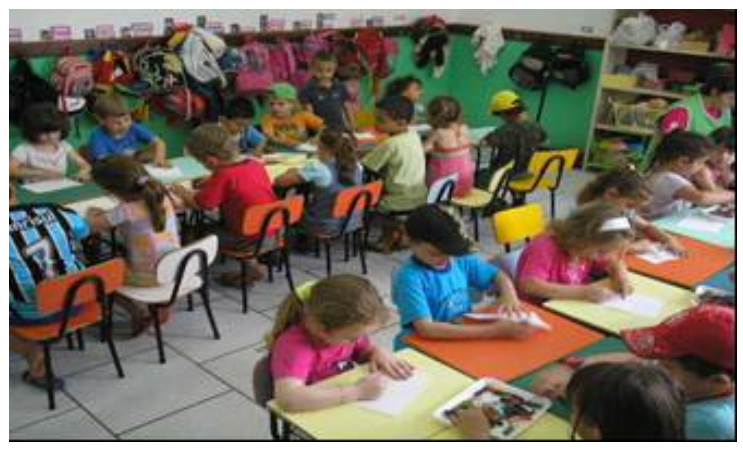

Figura 7 - Jardim I desenhando
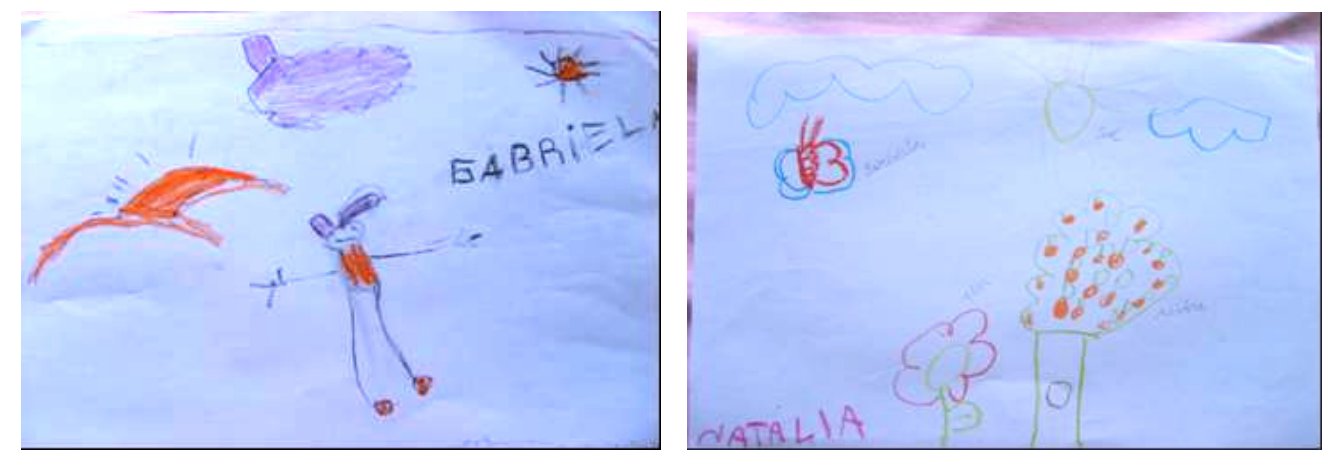

Figuras 8: Amostragem: Desenhos da natureza

Tudo indicou que o fato dos alunos perceberem diferenças entre o antes e depois; a simples prática de Educação Ambiental não foi em vão; foi colocado em exposição na escola desenhos e trabalhos dos alunos a respeito do meio ambiente e o que atitudes podem e devem tomar a respeito do Meio Ambiente. 


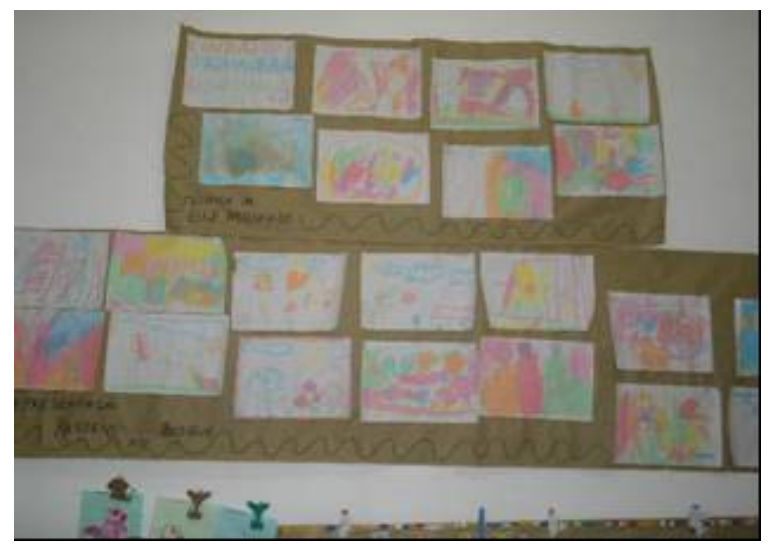

Figura 9 - Exposição dos desenhos: Passeio pelo Bosque e Adote um Jardim

\section{CONSIDERAÇÕES FINAIS}

Através desta pesquisa, ficou-se evidente que a temática ambiental precisa ser mais trabalhada na Educação Infantil com enfoque a realidade ambiental local, para que as crianças possam analisar e refletir seu papel na comunidade; conclui-se que com essa prática educativa desenvolvida de forma interdisciplinar, foram abertas novas possibilidades de como trabalhar a Educação Ambiental com as crianças da Educação Infantil, que tudo pode ser difícil ou fácil dependendo da ótica e perspectiva de cada um, pois se devem assumir riscos para ver que muitas vezes as consequências são melhores do que se esperava.

A História como ferramenta de Educação Ambiental é teoricamente trabalhada, professores afirmam nas entrevistas, que a História exerce papel importante na Educação Infantil, comentam que é importante as crianças aprenderem a cuidar do meio ambiente, para que possam se tornar adultos conscientes de seu papel no mesmo; mas não se tem uma receita formulada de como trabalhar tais questões e muitas vezes estas são deixadas de lado.

Foi observado que durante a realização deste projeto, a educação ambiental foi trabalhada com perspectiva e estímulo a cidadania; fazendo com que a criança refletisse suas atitudes diárias em relação ao meio ambiente escolar e através destas reflexões levarem exemplos para suas casas trabalhando assim a História das mudanças culturais, o que se deve fazer a respeito do Meio Ambiente e qual é seu papel na sociedade, engajando a criança para este fim; mudanças que poderão levar anos, mas que pequenas atitudes feitas na hora certa fazem a diferença.

Valorizando a formação de sujeitos críticos, capazes de interferir na sociedade, tendo como potencial, cidadãos sensibilizados de que o papel deles é cada dia valorizar o meio ambiente como parte importante de suas vidas, não isolá-lo.

O projeto executado foi um pequeno passo para a sensibilização das crianças em relação ao meio ambiente, bem como professores e funcionários, fazer com que os educadores repensem suas práticas, utilizando da simplicidade para que no futuro realizem projetos grandiosos; através das entrevistas, analisa-se que os professores possuem boa vontade em relação à educação ambiental, mas que muitas vezes falta comprometimento de que podem fazer a sua parte; mudanças de paradigmas e conceitos são atitudes a serem tomadas por aqueles que julgam não saberem fazer; mas primeiramente é necessário que queiram fazer algo a respeito; muitos educadores baseiam seus ensinamentos de forma tradicional e outros estão em transição do 
tradicional para o libertador muitas vezes ficando perdidos de como agir, o que fazer e que método seguir; práticas, planejamento interdisciplinar; saberes específicos e áreas afins devem ser trabalhadas de forma clara e objetiva, que a história deve ser trabalhada de forma int gada como parte integrante de um todo, mas que principalmente metas de Educação Ambient ejam efetivadas diariamente nas Escolas de Educação Infantil, pois quando bem trabalhadas na infância estas temáticas serão assimiladas e farão parte da vida deste sujeito em crescimento - a criança.

\section{REFERÊNCIAS BIBLIOGRÁFICAS}

BARCELLOS.S.B. Ações em Educação Ambiental e suas relações com a Interdisciplinaridade e cidadania: 0 caso do Projeto Social “Educação Ambiental na vila Kennedy”, no período de mar./09.2009. 95f.Monografia (Especialização em Educação Ambiental)-Universidade Federal de Santa Maria, Santa Maria, 2009.

KIST.A.F. "A Água numa perspectiva crítica da Educação Ambiental”: uma análise a partir da III Conferência Nacional Infanto-Juvenil pelo Meio Ambiente. no período 2009. 91f. Monografia (Especialização em Educação Ambiental)Universidade Federal de Santa Maria, Santa Maria, 2009

LOVELOCK, James. Aquecimento Global, a Terra Ardente. REVISTA PLANETA - CONHEÇA O MUNDO DESCUBRA VOCE, São Paulo, ano 33, Ed.414, março 2007.

MINISTERIO DA EDUCAÇÃO E DESPORTO. Referencial Curricular Nacional para a Educação Infantil: conhecimento de Mundo. V.3. Brasília: MEC/SEF, 1998.

MONTENEgRO, J. F ; DUARTE, F. C . Ação Coletiva na Sociedade de Risco. In: CONPEDI - Conselho Nacional de Pesquisa e Pós-Graduação em Direito, 2008, Salvador. Anais do Conpedi - 2008, 2008. Disponível em:< http://lattes.cnpq.br/>Acesso em 23 fev 2010.

NEFUSSI, Nelson; LICCO, Eduardo. Políticas de Saneamento e Meio Ambiente. 2000. Disponível em:<http://www2mre.gov.br/cdbrasil/ Acesso em: 26 abr.2009.

.Enchentes.Disponível

em: http://www2.mre.gov.br/cdbrasil/itamaraty/web/port/meioamb/mamburb/enchente/apresent.htm. $>$ Acesso em : 26 abr.2009.

PIAGET, J. A psicologia da criança. 17 ed. Rio de Janeiro: Bertrand Brasil, 2001.

SOARES, H.Pós - Modernidade e Exclusão. A Razão. São Paulo, 02 fev 2002. Disponível em http://www.angelfire.com/sk/holgonsi/ Acesso em 05 ago 2009

Pós - Modernidade, política e educação. A razão. Recife, 11 Nov 2005. Disponível em http://www.angelfire.com/sk/holgonsi/ Acesso em 05 ago 2009

Globalização: sobre os "Riscos de grande Consequencia" A Razão. [S.L], 07 dez 2000. Disponível em http://www.angelfire.com/sk/holgonsi/ Acesso em 05 ago 2009

Cidadania como um conceito de Totalidade.

http://www.angelfire.com/sk/holgonsi/ Acesso em 25 ago 2009
A Razão. [S.L] 10 set 1993. Disponível em A Razão .[S.L] jun 2001. Disponível em

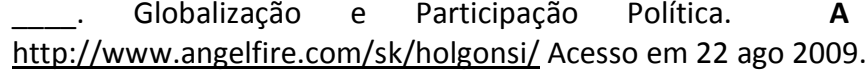

